\title{
Catequizadores de índios, educadores de colonos, Soldados de Cristo: formação de professores e ação pedagógica dos jesuítas no Brasil, de 1549 a 1759, à luz do Ratio Studiorum
}

Catechists of indigenous peoples, educators of colonists, Soldiers of Christ: teachers education and jesuitical pedagogical action in Brazil 1549-1759, according to Ratio Studiorum

\author{
Peri Mesquida ${ }^{1}$
}

\begin{abstract}
RESUMO
A presença dos jesuítas no Brasil Colônia, de 1549 a 1759, marcou indelevelmente nossa educação e nossa prática pedagógica. O Ratio Studiorum, compêndio de regras de como ensinar, como aprender, como administrar uma instituição de ensino, foi responsável pela construção de um verdadeiro sistema de ensino no território nacional, pois não somente homogeneizava a prática pedagógica, como estabelecia um único método de ensino/aprendizagem. O objetivo principal da pesquisa cujo relato apresenta-se sob a forma de artigo foi analisar criticamente o Ratio Studiorum de 1599, edição em inglês de 1870, e sua repercussão na formação de professores pela Companhia de Jesus no Brasil, assim como encontrar traços da prática pedagógica dos inacianos e sua influência sobre a sociedade no período estudado. Para tanto, lançou-se mão da historiografia que tivemos acesso, em especial Leite (1938), Lacouture (1994), Franca (1952), Schimitz (1994), entre outros, e de
\end{abstract}

${ }^{1}$ Doutorado em Ciências da Educação pela Université de Genève, Suiça. Professor convidado da Université de Genéve e Visitante da Université de Fribourg (Suíça). Professor Titular do Programa de Pós-Graduação Stricto Sensu em Educação da Pontifícia Universidade Católica do Paraná, Brasil. E-mail: mesquida.peri@gmail.com 
fontes documentais de apoio, utilizando basicamente a crítica hermenêutica para a análise, a interpretação e a crítica dos dados coletados, chegando a algumas conclusões preliminares, como o fato de que a ação pedagógica dos jesuítas incorporou-se na prática pedagógica no Brasil, marcando-a indelevelmente. A pesquisa mostrou também que a educação foi escolhida como opção preferencial assumida pela Companhia de Jesus desde a sua origem, e a forma como o ensino fundado no Ratio, tendo como base teórica o tomismo-aristotélico, auxiliou a conformar a sociedade à cultura luso-europeia, baseada na ordem, na disciplina, na obediência, na autoridade, no respeito hierarquizado às regras.

Palavras-chave: jesuítas; educação; colégios; Ratio Studiorum.

\begin{abstract}
The presence of the Jesuits in Brazil, from 1549 to 1759, has indelibly marked our education and our teaching practice. The Ratio Studiorum, a compendium of rules of how to teach, and learn how to administer an educational institution, was responsible for building a true system of education in the country, because it did not only homogenize the educational practice, but it also established a unique method of teaching-learning. The main objective of the research report which is presented in the form of article was to analyze critically the Ratio Studiorum of 1599, the English edition of 1870, and its impact on teacher education by the Jesuits in Brazil, as well as to find traces of the Ignatian pedagogical practice and its influence on society in the period studied. For this purpose, we used the historiography that we had access to, in particular Leite (1938), Lacouture (1994), Franca (1952), Schmit (1994), among others, and documentary sources of support, primarily using the hermeneutics critics to the analysis, interpretation and critical analysis of data collected, up to some early findings, like the fact that the pedagogical action of the Jesuits was incorporated in the teaching practice in Brazil, marking it indelibly. The research also showed that education was chosen as the preferred option taken by the Society of Jesus, since its inception, and how education, based on the Ratio, with the theoretical base on the Aristotelian Thomism, helped to shape the Brazilian society as a Portuguese European culture, based on order, discipline, obedience, authority, respect to hierarchical rules.
\end{abstract}

Keywords: Jesuits; education; schools; Ratio Studiorum. 


\section{Introdução}

A Companhia de Jesus, ou Societatis Iesu, teve início a partir de um pequeno grupo de homens (Afonso Salmeron, Diogo Laines, Francisco Xavier, Nicolau Babdilha, Pedro Fabro e Simão Rodrigues) que se reuniam com Inácio de Loyola, o qual, a exemplo dos demais, estudava na Universidade de Paris, para refletirem sobre os Exercícios Espirituais, obra que Loyola escrevera na década de 1520.

Serafim Leite conta que, no dia 15 de agosto de 1534, o grupo reunido na capela de Nossa Senhora, em Montmartre, Paris, resolveu fazer os seguintes votos: castidade, pobreza, peregrinação a Jerusalém, ocupar a vida e forças na salvação do próximo, administração dos sacramentos da confissão e da comunhão, pregação e celebração da missa, "tudo sem estipêndio" (LEITE, 1938, p. 5). Desses votos, não puderam pôr em prática a ida à Terra Santa, considerada por eles como uma verdadeira vocação. Assim, depois das peregrinações pela Espanha e Veneza, foram para Roma onde resolveram fundar a Companhia de Jesus, em 1539. De julho a agosto desse ano

Inácio, Favre, Codure, põem-se ao trabalho, e redigem um documento a ser apresentado ao Papa, cuja aprovação é a única que pode conferir existência oficial à organização. Será a Prima Societatis Iesu Instituti summa (LACOUTURE, 1994, p. 103).

O autor comenta as palavras que nomearão a nova ordem religiosa e educadora a ser oficializada: "Societatis" e "Compañia". E faz a seguinte observação:

Há quatro séculos os seus membros apõem à sua assinatura as duas letras S.J., a primeira das quais se refere à 'sociedade'. Será porque a maioria dos fundadores pensava em espanhol e tinha em mente a palavra compañia, que não possui equivalente em latim, e teve de adotar societas. Se pretendiam revesti-la de um sentido 'militar', a palavra 'legio' não seria mais apropriada? (LACOUTURE, 1994, p. 103).

Na realidade, a Ordem é conhecida, seja por Companhia, seja por Sociedade. A primeira nomenclatura indica que os jesuítas estão a serviço do exército 
de Javé, constantemente prontos para o combate em favor do Evangelho e, é claro, contra o protestantismo e a ignorância; a segunda propõe uma associação de companheiros irmanados pela vocação da qual se dizem comissionados, a de contribuir para a expansão do catolicismo pelo Saber, ad majorem Deum gloriam! [para a maior glória de Deus!].

No ano seguinte, no dia 27 de setembro de 1540, o Papa Paulo III oficializou a Sociedade como ordem eclesiástica por meio da bula Regimini Militantis Ecclesiae. Dez anos mais tarde, em 21 de julho de 1550, a bula Exposcit Debitum, do Papa Júlio III, aprovou a Formula Instituti da Societatis Iesu, confirmando a Companhia de Jesus. De acordo com o padre Francisco Rodrigues, em sua História da Companhia de Jesus na Assistência de Portugal, Volume I, Tomo I, na Formula Instituti, Inácio de Loyola lançava o seguinte apelo:

Todo aquele que nesta nossa Companhia, que desejamos seja assinalada com o nome de Jesus, quiser militar como soldado de Deus, debaixo da bandeira da Cruz e servir ao único Senhor e ao Romano Pontífice, Vigário Seu na terra, depois de fazer voto solene de castidade perpétua, assente... propagar a fé pela pública pregação e ministério da palavra de Deus, pelos exercícios espirituais e obras de caridade, e nomeadamente ensinar aos meninos e rudes as verdades do cristianismo [...] (RODRIGUES, 1931, p. 110-112).

Dessa maneira, o ensino passou a ser a grande vocação dos soldados da Companhia de Jesus, a qual, diferente das ordens monacais, seria uma ordem missionária a anunciar ao mundo a palavra de Cristo pelo Logos do saber, em instituições formais de ensino e pela catequese como educação informal, justamente quando a Igreja precisava de uma Ordem educadora para fazer frente ao avanço do protestantismo, no movimento da contrarreforma, oficializado pelo Concílio de Trento (1545-1563), mas em operacionalização desde a década de 1520. O protestantismo acreditava na educação como instrumento fundamental para o entendimento da Palavra de Deus, pois, segundo ele, o homem moderno precisava saber ler e escrever para ter acesso às Sagradas Escrituras, traduzidas para o vernáculo por Martinho Lutero, mas também para participar da vida em sociedade entendendo, pela leitura, o código escrito e sabendo expressar-se por ele (MESQUIDA, 1994, p. 148). Foi assim, munidos das armas da educação, que os Soldados de Cristo chegaram ao Brasil, em 1549, fazendo parte da expedição colonizadora de Tomé de Souza, país onde iriam permanecer durante duzentos e dez anos, ininterruptamente, como os únicos professores de colonos e índios. 
Eles traziam na bagagem uma formação nitidamente parisiense, humanista, escolástica, focada na ordem e na disciplina e, em especial, nas Constituições da Companhia e nos Exercícios Espirituais de Inácio de Loyola. A rigor, uma educação cuja teoria e cuja prática pedagógica continuam a se fazer presentes nas salas de aula ainda hoje.

\section{Os Soldados de Cristo e a opção preferencial pela educação}

Na sua obra Pedagogía de los jesuitas en la ratio studiorum, Miguel Bertrán Quera escreve que, para Inácio de Loyola, o primeiro a sugerir a opção pela educação foi o padre Diego Laínez (ou Diogo Laines, em Portugal), em 1539. Laínez tem uma biografia significativa, pois, à semelhança de Loyola, cursou a Universidade de Paris, participou do grupo que discutia com o fundador os Exercícios Espirituais, foi assessor teológico do Papa durante o Concílio de Trento, convocado por Paulo III, tendo sido, ainda, vigário-geral da Ordem dos Jesuítas após a morte de Loyola, em 1556, e representou a Igreja Católica no Colóquio de Poissy (1561), na polêmica contra os calvinistas, do qual saiu a sua obra máxima, intitulada Disputationes Tridentinae (QUERA, 1984, p. 35).

Foi, então, a partir de 1539 que a Companhia de Jesus tomou para si a missão de desenvolver a ação educativa como tarefa preferencial, em particular pela fundação de colégios, escolas, universidades, seminários.

O primeiro colégio foi fundado em Messina, na Itália, no ano de 1548, por Jerônimo Nadal e um grupo de jesuítas, especialmente enviados àquela localidade para a fundação daquele estabelecimento de ensino, o qual teria como finalidade a formação de um laicato culto para o serviço da Ordem e da Igreja. No entanto, o Colégio Romano foi o marco fundante da opção pela educação feita pelos Soldados de Cristo, tendo sido instalado graças à obtenção de uma doação do Duque de Gandia, Francisco de Borja, em 1551, "em uma casa alugada na Via del Campidoglio, onde se lia numa tabuleta, a seguinte inscrição: 'Scuola di grammatica, d'humanitá e di dottrina cristiana, gratis", cujo primeiro reitor foi P. Pelletier (FRANCA, 1952, p. 10). Naquele mesmo ano, 1551, Loyola escreveu uma carta a toda a Companhia recomendando a fundação de colégios em todos os lugares onde os jesuítas desenvolviam sua ação missionária, ocupando, então, a escola um lugar significativo, senão primordial, na vocação missionária da Companhia. Por isso, para Rômulo Vasco da Gama de Carvalho (2001, p. 24), autor de importante história do ensino em Portugal, a Igreja queria uma 
[...] autêntica milícia, um laborioso exército de homens de religião, que vivessem só para ela, no permanente alerta da prevenção combativa. $\mathrm{O}$ exército surgiu na hora própria. Chamou-se Companhia de Jesus e o seu comandante supremo foi Inácio de Loyola.

A preocupação da Companhia de Jesus foi utilizar o saber para reproduzir e expandir a doutrina católica, além de servir como uma arma importante na luta contra a difusão do protestantismo que se expandia, tendo a educação como elemento fundamental para a transmissão de valores, ideias e doutrinas.

A exemplo do Colégio Romano, a orientação de Inácio de Loyola era de que as instituições de ensino da Companhia oferecessem educação gratuita, mantidas seja pelo Estado, seja por doações de particulares ou de entidades interessadas na expansão do catolicismo. Entre as entidades que desde o início, em Portugal, contribuíram para a manutenção dos colégios dos jesuítas, está a Ordem do Templo, ou dos Templários (presente em Portugal desde 1319), que ajudou na manutenção dos Colégios da Baía e do Rio de Janeiro, como esclarece Serafim Leite (1938, p. 117):

As rendas dos colégios da Baía e do Rio de Janeiro são assinadas sobre certa redízima dos engenhos de açúcar, porque o Rei de Portugal, como Mestre da Ordem de Cavalaria de Jesus Cristo, por autorização apostólica, recebe a dízima destas partes. E, para pagamento das rendas dos Colégios sobreditos, ordenou El-Rei uma dízima sobre os ditos dízimos, a qual assinou aos Padres dos ditos Colégios.

A expansão dos colégios dos Jesuítas foi significativa, pois, quando Inácio de Loyola faleceu, a Sociedade já havia fundado mais de 33, muitos deles no Brasil, como o Colégio da Baía (1549), Colégio dos Meninos de Jesus, de São Vicente (1553), Colégio do Espírito Santo (1555), Colégio de Porto Seguro (1552), além do Colégio de Piratininga, em 1550, quando o padre Leonardo Nunes começou "nos Campos de Piratininga, a ensinar a falar português, a ler e escrever, passando, em 1554, para São Paulo de Piratininga" (LEITE, 1938, p. 223). Dessa maneira, a opção pela educação como instrumento da missão, passou a ser regra na Companhia ao ponto de as "palavras 'jesuíta' e 'educador' se tornarem sinônimos, maciçamente sinônimos" (LACOUTURE, 1994, p. 124).

A Sociedade, ou Companhia de Jesus, procurou, desde a sua fundação, elaborar as bases teóricas da sua prática pedagógica, o método adotado e as 
regras que iriam nortear a ação educativa. Estas se consubstanciaram no que ficou conhecido por Ratio Studiorum, tendo como modelo as Constituições, em especial o seu capítulo IV, os Exercícios Espirituais de Inácio de Loyola, e o modus parisiensis como método capaz de ensinar de forma rápida e perfeita. Podemos dizer que a elaboração do Ratio definitivo, aquele que iria universalizar uma peculiar forma de educar, constituindo um sistema de ensino, é fruto de uma "caminhada" de meio século. O primeiro Ratio Studiorum deve-se a Jerônimo Nadal e foi elaborado em 1548, o segundo foi o Ratio de Aníbal Coudret, em 1551, o terceiro, o Ratio de Diego de Ledesma, de 1553 (De ratione et ordine studiorum collegii romani), o quarto é o Ratio de Borja, elaborado em 1573, tendo como título Summa Sapientia, a elaboração do quinto Ratio coube ao padre Cláudio Aquaviva, em 1586. Finalmente, aparece o Ratio de 1591, uma preparação para o Ratio definitivo publicado em 1599, depois de uma rigorosa consulta aos "doutos" da Companhia. Esse Ratio regulamentou o ensino da Companhia de Jesus até a suspensão da Ordem, em 1773, pelo Papa Clemente XIV, que o fez sob pressão, em particular dos reinos de Portugal e Espanha. O Papa Pio VII restaurou a Sociedade de Jesus, em 1814, por meio da Bula Sollicitudo Omnium Ecclesiarumm com a seguinte justificativa: "Declaramos e damos poder para que eles (os jesuítas) possam livremente aplicar-se à educação da juventude nos princípios da fé católica, para formá-la em boa moral, e dirigir colégios e seminários" (VERCESI, 1933, p. 38). Com isso, a Igreja reconhece a contribuição que os jesuítas haviam dado para a educação católica e a necessidade de manter em atuação uma Ordem eminentemente consagrada à educação e ao ensino.

No entanto, a base filosófica do Ratio Studiorum de 1599 foi, sem dúvida alguma, o pensamento tomista-aristotélico (Aristóteles: 384-322 a.C.; Tomás de Aquino: 1227-1273). As seis categorias filosóficas básicas de Aristóteles - ato e potência, causa material, causa formal, causa eficiente e causa final - fundamentaram a prática pedagógica consubstanciada no Ratio. Assim, a concepção do ensino/aprendizagem alicerçada na metafísica tomista-aristotélica gera um monólogo pedagógico - professor (causa eficiente) para os alunos (causa material) - cabendo ao aluno apreender o conhecimento transmitido e, eventualmente, dar resposta às questões colocadas pela autoridade pedagógica. A resposta final, contudo, é prerrogativa do mestre, adulto acabado, potência atualizada. Ele é o escultor que possui a ideia da obra. O aluno (aquele que é destituído de luz) é a pedra que, sob a ação do mestre-escultor, tomará a forma que a causa eficiente lhe der. Enquanto matéria sem forma final, o discípulo é um elemento passivo que se con-formará, pouco a pouco ao modelo que está na mente do mestre. Assim, a ação pedagógica nada cria de novo, é reprodutora do conhecimento acumulado (MESQUIDA, 2006, p. 3). 
A prática pedagógica está, portanto, centrada no mestre-escultor. Este, manipulando com "maestria" a linguagem, procurará "imprimir" no discípulo, con-vencendo-o com argumentos inquestionáveis, o saber do qual ele, mestre, é o guardião. Mesmo sem ser necessariamente uma folha em branco à espera de que lhe seja impresso o conhecimento, o discípulo é uma matéria informe que aguarda o momento de ter as suas potencialidades "estimuladas" pelo cinzel do escultor. Este dará à "matéria" a forma cujo modelo está no seu pensamento (ou no livro-texto) (MESQUIDA, 2006, p. 4).

\section{A formação de professores no Ratio Studiorum de 1599}

$\mathrm{Na}$ Companhia de Jesus tudo era baseado em regras, disciplina, ordem, e o Ratio apontava constantemente para a observância das normas de uma prática pedagógica eficiente, tanto na formação de professores quanto na sua ação docente. Daí que o Ratio Studiorum, de 1599, apresenta o seguinte sumário: Regras do Provincial; Regras do Reitor; Regras do Prefeito (de Estudos Superiores); Regras Comuns a todos os Professores de Faculdades Superiores; Regras Particulares dos Professores de Faculdades Superiores (Professor de Escrita, Professor de Hebreu, Professor de Teologia, Professor de Casos de Consciência ou Teologia Moral); Regras dos Professores de Filosofia (Professor de Filosofia, Professor de Filosofia Moral, Professor de Matemática); Regras do Prefeito de Estudos Inferiores; Regras dos Exames Escritos e Prêmios; Regras Comuns aos Professores das Classes Inferiores; Regras Particulares dos Professores das Classes Inferiores (Professor de Retórica, Professor de Humanidades, Professor de Gramática Superior, Professor de Gramática Média, Professor de Gramática Inferior); Regras dos Estudantes da Companhia; Regras dos que Repetem a Teologia; Regras do Bedel; Regras dos Estudantes Externos; Regras das Academias; Regras do Prefeito (Academia de Teologia e Filosofia); Regras do Prefeito desta Academia (Academia de Retórica e Humanidades, Academia dos Gramáticos, Ordenação para os Estudos Superiores) (RATIO STUDIORUM, 1559/1870).

Dos seis primeiros jesuítas a chegarem ao Brasil, em 1549, quatro haviam cursado a Universidade de Paris, preparando-se em teologia, filosofia e humanidades para exercerem a prática pedagógica a serviço da Missão. Depois deles, os demais eram formados seja por aquela Universidade, seja por outras instituições universitárias, de preferência fundadas pela própria Companhia. Muitos deles, após a fundação do Colégio Romano, passaram a receber a formação pedagógica e geral naquela instituição da Sociedade de Jesus. Portanto, 
a formação de professores era levada extremamente a sério. Tanto que no Ratio Studiorum há um conjunto de regras que indica a formação que o professor de cada disciplina deve ter, como podemos observar pelo sumário do Ratio. A Regra n. ${ }^{0} 13$, do professor de teologia, diz que não "basta fazer referência às opiniões dos doutos e calar a respeito da sua própria; defendei a opinião de São Tomás ou então não vos refirais a ela" (RATIO STUDIORUM, 1559/1870, p. 37), dando ênfase não somente à importância que o pensamento de Tomás de Aquino deve ter para os professores como também ao conhecimento geral e aprofundado que os professores precisam possuir do tema que lhes compete ensinar.

O Ratio exige que os professores de todas as disciplinas se mantenham fiéis aos autores tradicionais recomendados pela Igreja e não procurem as novidades "modernas": "Os professores que tenham tendência para novas doutrinas, ou sejam liberais demais, devem ser excluídos do ensino" (RATIO STUDIORUM, $1559 / 1870$, p. 4), o que reflete uma formação que os mantém no quadro da ortodoxia católica. A Regra $\mathrm{n}^{\circ}{ }^{\circ} 6$, do professor de matemática, é esclarecedora a esse respeito: "Esforçai-vos para que os novos professores mantenham os métodos de ensino dos seus antecessores" (RATIO STUDIORUM, 1559/1870, p. 46).

Os formadores dos educadores jesuítas, ou os docendi peritissimis, deveriam fazer uso preferencial da prelectio, ou seja, da preleção, na sua prática pedagógica, exercitando, em primeiro lugar, a capacidade de memorização do estudante, de acordo com a Regra n. ${ }^{\circ} 5$, do professor de gramática do Ratio Studiorum (1559/1870, p. 86): "The method of the prelection shall be as follow", procurando assim levar os alunos a repetirem ao máximo a matéria de forma a exercitar a memória. Depois disso tinha início a composito, que nada mais é do que a reprodução do modelo apresentado pelo professor. Daí, uma regra fundamental: "Imitatio est anima prelectionis" ["A imitação é o que anima a preleção"], em uma tradução livre. Finalmente, a décima quarta regra do Provincial prescreve que "no final do ano será feita a repetição de todas as aulas" (RATIO STUDIORUM, 1559/1870, p. 86).

O professor jesuíta precisa ter uma sólida formação em humanidades e gramática, assim como em retórica: "Não dispense o Provincial os nossos escolásticos do ensino de gramática e de humanidades" - Regra n. ${ }^{\circ} 26$ do Provincial, Ratio Studiorum (1559/1870, p. 10): "By that same token, the provincial is not to excuse our scholastics from teaching grammar ou humanities". Da mesma forma com relação ao aprendizado da língua divina, o latim: "Zele com diligência para que se conserve entre os futuros professores o uso do latim, e desta regra não haja dispensa [...] igualmente, que os nossos escolásticos quando escrevam cartas aos da casa, o façam em latim" - Regra n. ${ }^{\circ} 8$, do Provincial, Ratio Studiorum (1559/1870, p. 16): "He shall take care that at home our scholastics keep up the practice of speaking latin [...] when our scholastics who are still in their studies 
write to other scholastics they shall do so in latin". A importância da expressão oral e escrita na língua sagrada é uma característica do aprendizado oferecido aos futuros professores da Companhia. Mesmo o uso das artes, em particular das artes cênicas, recomendado com cautela pelo Ratio, deverá ser feito em latim: "No que diz respeito às tragédias e comédias, que deve ser raro, e somente em latim", conforme a Regra n. ${ }^{\circ} 20$ do Provincial (RATIO STUDIORUM, 1559/1870, p. 10). Nessa mesma regra há uma proibição explícita à utilização de personagens femininos, dizendo literalmente: "personagens e hábitos femininos são proibidos" (RATIO STUDIORUM, 1559/1870, p. 92?). Afinal, o futuro professor jesuíta precisa ficar afastado das mulheres para que não caia na tentação da prevaricação.

O reitor das instituições de formação de professores é exortado a encorajar na "sagrada vocação do magistério" os futuros soldados educadores, pois deles depende o sucesso da causa. A Regra n. ${ }^{\circ}$ 20, do Reitor, diz o seguinte: "Procure, diligentemente, com sua caridade religiosa, manter o entusiasmo dos professores e vele para que não sejam sobrecarregados com os trabalhos caseiros" (RATIO STUDIORUM, 1559/1870, p. 92?), isso porque um professor satisfeito e alegre desempenhará, na visão do Ratio, com prazer, a sua vocação.

$\mathrm{Na}$ formação do educador jesuíta há um lugar especial para a disciplina e a obediência. Ele é um defensor e mantenedor da ordem, pois observa as regras da Companhia, de acordo com o Ratio: "Não há nada que mantenha a disciplina como a observação das Regras", diz o Ratio nas Regras Comuns aos Professores das Classes Inferiores (RATIO STUDIORUM, 1559/1870, p. 94?). Assim, a observância das regras, com zelo e cuidado, é um remédio mais poderoso para a indisciplina do que os castigos. Mas, estes, quando necessários, podem ser aplicados. Por isso, o professor é formado na prudência para "não ser precipitado no castigar nem demasiado no inquirir, isso fará com que ele não aplique nenhum castigo físico, mas abstenha-se de qualquer injúria, por palavras e atos. Ao Prefeito, deixe os castigos mais severos, sobretudo por faltas cometidas fora de aula" - Regras números 39 e 40 do Ratio Studiorum (1559/1870, p. 70). Essas regras colocam em dúvida a afirmação de Jacques-Barthélemy de Salgues (1827, p. 199), em sua obra "L'antidote de Montrouge", na qual chama os jesuítas de orbilianistas, isto é, de adeptos dos "castigos corporais".

\section{Catequizadores de índios, educadores de colonos}

Cientes da missão de que estavam investidos, os jesuítas, ao chegarem ao Brasil, em 1549, iniciaram imediatamente a ação pedagógica, pela catequese, endereçada aos índios e pela fundação de colégios, visando os filhos dos colonos. 
São muitas as narrativas encontradas nos documentos pesquisados, em particular nas cartas de Nóbrega e de José de Anchieta, que comprovam a ação catequética missionária que os jesuítas pioneiros desenvolviam com os autóctones. Aproximavam-se dos índios com a intenção de "salvar as suas almas" pela catequese, passando, pouco a pouco, a lhes ensinar as primeiras letras e a prática de ofícios, pois os inacianos precisavam de mão de obra "especializada" nas suas fazendas (LEITE, 1938, p. 185).

Em uma carta enviada ao vigário-geral, em Portugal, Anchieta dá mostras de como lhes é pesado o desenvolvimento da missão: "Andamos mais de cem léguas padecendo fome e sede sem deles pretendermos mais do que a salvação das suas almas e a glória de Deus" (ANCHIETA, 1933, p. 38). No entanto, tudo valia a pena, se fosse feito pela "Glória de Deus". A "salvação das almas" dos índios era possível pela catequese enquanto educação informal, utilizando as regras do Ratio e, não poucas vezes, as artes cênicas como instrumento pedagógico. Leite (1938, p. 58) escreve que "o fim com que os jesuítas foram ao Brasil, foi a catequese [...] a instrução foi um meio". Da mesma forma, Nóbrega (1931, p. 45) diz: "Convidamos os meninos a ler e escrever e conjuntamente lhes ensinamos a doutrina cristã". Portanto, "a escola de ler, escrever e cantar" fazendo parte do ensino primário "pode e deve considerar-se como prolongamento da catequese" (LEITE, 1938, p. 72). O ensino das primeiras letras era fundamental não somente para que os índios pudessem ler os escritos da Companhia (não as Sagradas Escrituras, pois o seu acesso estava restrito aos religiosos e nem a todos!) e acompanhar os Cânticos escritos, entoando-os, mas também como uma forma de inculcar a cultura letrada do colonizador. Da mesma maneira, o ensino de ofícios, em particular nas reduções, fazia dos índios colaboradores indispensáveis dos jesuítas, nas fazendas e na construção de colégios, como assevera Manuel da Nóbrega (1931, p. 12):

Desde logo se fez a paz com o gentio da Terra. Os mesmos índios da Terra ajudam a fazer as casas e as outras coisas em que se queira empregá-los; podem-se já contar umas cem casas e se começam a plantar cana-de-açúcar e muitas outras coisas para o mister da vida.

Os jesuítas não somente defendiam os índios das investidas escravagistas de portugueses (no caso, seus concorrentes) e, mais tarde, espanhóis, como o povo da terra os auxiliava no combate aos eventuais invasores. No seu livro História de uma Viagem feita à terra do Brazil, o suíço Jean de Léry, pastor calvinista, partícipe da expedição de Nicolau Durand de Villegagnon, em 1556, 
conta que Anchieta e Nóbrega auxiliaram Estácio de Sá a combater os franceses da "França Antártica", colocando na linha de frente da batalha os índios Tupinambás (LÉRY, 1889, p. 228).

Da mesma forma que nutriam uma amizade missionária com os índios, os jesuítas ensinavam-lhes as primeiras letras e exercitavam a catequese. Essa amizade era compensada pela participação dos índios no combate aos "hereges" protestantes invasores e na manutenção das fazendas.

A educação formal por meio dos colégios, dedicada aos filhos dos colonos, tinha dupla finalidade, tal como as demais instituições de ensino dos inacianos, que era fomentar o espírito religioso católico e manter a cultura portuguesa, como observa Paiva (2000), fazendo com que permanecesse intacta também a união entre a bíblia e a espada, o trono e o altar.

No ambiente do colégio, o Ratio era A REGRA, com o seu apego à disciplina, à ordem, à obediência, à marcação do tempo, para que a mente não ficasse desocupada ("cabeça desocupada, oficina do diabo"), e à hierarquia. Tratava-se, portanto, de não somente manter a cultura, como conservar o indivíduo no quadro dos padrões da sociedade metropolitana. Por isso, a "corrida" de maratona na fundação de colégios, com a maior rapidez possível e a urgência em conceder títulos, mesmo à revelia das normas universitárias portuguesas: Baía: 1549; em 1550, nos Campos de Piratininga, o padre Leonardo Nunes começa a ensinar as primeiras letras; Porto Seguro, em 1552, fundado pelo padre Navarro; em 1553, o padre Manuel da Nóbrega funda o Colégio dos Meninos de Jesus, em São Vicente, em 1554 e no mesmo ano outro, em São Paulo de Piratininga, e assim por diante.

Adiantando-se à criação de uma universidade, os jesuítas outorgaram, em 1578, os primeiros graus acadêmicos de que se tem notícia na América Portuguesa, escreve Leite (1938). Tratava-se do grau de Mestre em Artes, tendo a solenidade contado com a presença do Governador Geral e do Bispo do Brasil. Foi assim que, em 1583, surgiu a ideia de transformar o Colégio da Baía em universidade, pensamento que, no entanto, não se materializou (LEITE, 1938).

A rigor, os jesuítas foram os únicos responsáveis oficiais pela educação formal no Brasil durante duzentos e dez anos, formando uma elite letrada que dava continuidade aos seus estudos em Portugal, na Espanha ou na França. Na realidade, os colégios dos Soldados de Cristo, tendo o Ratio como base indicativa de teoria e prática fundada na metafísica do tomismo-aristotélico, consolidaram no Brasil uma educação centrada no professor, autoridade máxima no processo pedagógico, pois ele, o mestre, é o detentor do saber acumulado. Sua tarefa, parte da missão da igreja de Cristo, é dar forma à matéria (aluno) atualizando suas potencialidades. Isso se realizava por meio de um discurso bem articulado, lógico, inquestionável (respeito à autoridade pedagógica): um verdadeiro 
monólogo pedagógico, pois o ensino era visto como a transmissão do conhecimento (pela prelectio) do adulto (homem acabado, atualizado para os jovens (em formação), constituindo-se em uma "pedagogia da resposta" (MESQUIDA, 2006, p. 5). Na medida em que o aluno é um recipiente do conhecimento, cuja única atividade é a memorização pelos exercícios mnemônicos os mais diversos, a ação de pensar e refletir autonomamente fica prejudicada, inibindo a criação e, portanto, estimulando a formação de consumidores do saber em detrimento da produção. Com isso, o ensino nada mais é do que a reprodução do saber acumulado, sem que os partícipes do processo educativo sejam responsáveis pela elaboração do conhecimento.

Essa ação pedagógica (ou melhor, ato pedagógico) “contribuiu para manter o vínculo entre a oligarquia e o modo de produção que a alimenta", mantendo ao mesmo tempo "vícios que perduram até hoje, inibem a capacidade de criar e produzir, porque não valorizam a iniciativa, a curiosidade intelectual, a observação, a reflexão, a crítica, a pesquisa" (MESQUIDA, 2006, p. 5-6).

\section{Considerações finais}

A expulsão dos jesuítas, em 1759, por ordem do marquês de Pombal, não eliminou do solo brasileiro a influência da prática pedagógica dos inacianos. Isso porque o modo de produção capitalista não foi implementado em Portugal, pois o período pombalino, a despeito das reformas realizadas, não teve o poder de colocar Portugal sobre os "trilhos do progresso". A classe social dominante em Portugal, constituída pela nobreza e por uma aristocracia ociosa e conservadora, não permitiu que as reformas pombalinas tivessem o efeito prático de mudar o modo de produção feudal em vigor. Destarte, a união entre a Igreja e o Estado que, no Brasil, perdurou até 1890, contribuiu para conservar os princípios pedagógicos dos jesuítas. A Igreja, durante esse período, aliada do Estado, esteve sempre empenhada em manter o status quo dominante. O Estado, primeiro a corte portuguesa e depois a monarquia brasileira, soube utilizar inteligentemente os intelectuais, clérigos e leigos, sobretudo os professores e bacharéis, para manter o domínio político e econômico das oligarquias "ilustradas". Assim, a elite letrada no Brasil, no período estudado, ajudou os "senhores" a se manterem como donos do poder, instrumentalizando-se do saber como poder e da autoridade que este lhes concedia para a manutenção de uma "ordem" fundada na disciplina e na obediência. 
Por isso, se os jesuítas foram catequistas missionários dos índios, dos brasileiros, não permitindo sua escravização pelos portugueses sempre que possível, mas aproveitando continuamente sua força de trabalho, ensinando-lhes as primeiras letras e os ofícios domésticos, mas utilizando-se da sua mão de obra, pois o trabalho era uma estrada que os levaria ao céu, foram também os educadores dos colonos, responsáveis pela formação de uma elite que iria subdirigir o território e manter-se no alto da hierarquia política, social e econômica: o saber a serviço do poder e da autoridade.

\section{REFERÊNCIAS}

ANCHIETA, José. Cartas, informações, fragmentos históricos e sermões. Rio de Janeiro: Civilização Brasileira, 1933.

CARVALHO, Rômulo de. História do ensino em Portugal: desde a fundação da nacionalidade até o fim do regime de Salazar-Caetano. Lisboa: Fundação Calouste Gulbenkian, 2001.

FRANCA, Leonel. O método pedagógico dos jesuitas. Rio de Janeiro: Livraria Agir Editora, 1952.

LACOUTURE, Jean. Os jesuitas. Porto Alegre: L\&PM Editores, 1994. v. 1.

LEITE, Serafim. História da Companhia de Jesus no Brasil. Rio de Janeiro: Civilização Brasileira, 1938.

LÉRY, Jean de. História de uma viagem feita à terra do Brazil. Revista do Instituto Histórico e Geográfico Brasileiro, n. 52, São Paulo: Editoração Eletrônica, p. 85-102, 1889.

MESQUIDA, Peri. Hegemonia Norte-Americana e Educação Protestante no Brasil. Juiz de Fora/São Paulo: Edufjf/Editeo, 1994.

. Os soldados de Cristo, a metafísica e a educação no Brasil. Texto didático utilizado no curso de pedagogia. Curitiba, 2006.

NÓBREGA, Manuel da. Cartas do Brasil. Rio de Janeiro: Officina Industrial, 1931.

PAIVA, José Maria de. Transmitindo cultura: a catequização dos índios no Brasil, 1549-1600. Revista Diálogo Educacional, Curitiba: Editora Champagnat, v. 1, n. 2, p. 135-156, jul./dez. 2000.

QUERA, Miguel Bertrán. Pedagogia de los jesuitas en la ratio studiorum: la fondación de colégios, orígenes, autores y evolución historica de la ratio. San-Cristóban: Universidad Católica de Táchira, 1984. 
RATIO ATQUE INSTITUTIO Studiorum Societatis Iesu Index Regularum, 1599. Washington: Conference of Major Superiors Jesuits, 1559/1870.

RODRIGUES, Francisco. História da Companhia de Jesus na Assistência de Portugal. Porto: Apostolado da Imprensa, 1931. v. I e II.

SALGUES, Jacques-Barthélemy. L'andidote de Montrouge. Paris: Moutardier, 1827.

SCHIMTZ, Egídio. Os jesuítas e a educação. São Leopoldo: Unisinos, 1994.

VERCESI, Ernesto. Pio VII: Napoleone e la restaurazione. Torino: Societá Editrice Internazionale, 1933.

Texto recebido em 07 de fevereiro de 2010.

Texto aprovado em 21 de julho de 2010. 